\title{
APONTAMENTOS SOBRE OS PRINCÍPIOS DE JUSTIÇA EM JOHN RAWLS A PARTIR DE UMA TEORIA DA JUSTIÇA
}

\author{
Juliana Lazzaretti Segat ${ }^{1}$ \\ Valmor Scott Jr. ${ }^{2}$
}

\begin{abstract}
RESUMO
A obra Uma teoria de justiça, de John Rawls, representou, no século XX, um divisor de águas na filosofia política e moral. O artigo objetiva abordá-la de maneira resumida, lançando luz à ideia dos dois princípios de justiça que, segundo o autor, seriam escolhidos em uma posição inicial de igualdade. Inicialmente, é feita uma breve abordagem sobre a posição original. Após, aborda-se o objeto dos dois princípios de justiça (a estrutura básica da sociedade), para, posteriormente, fazer uma incursão sobre esses princípios. Em termos metodológicos, trata-se de pesquisa de cunho qualitativo, por meio de revisão bibliográfica.
\end{abstract}

Palavras-chave: John Rawls, Princípios de justiça, Liberdades iguais, Igualdade democrática, Princípio da diferença.

\section{NOTES ON THE TWO PRINCIPLES OF JUSTICE IN JOHN RALWS'S THEORY OF JUSTICE}

\begin{abstract}
John Rawls' Theory of Justice was a watershed moment in political and moral philosophy in the twentieth century. This study reviews the literature qualitatively analyzing the two concepts of justice suggested by the author, especially in regards the choices available in a context of an equal-start. It begins briefly discussing the concept of original position, followed by a combined analysis of justice and its object (society's basic structure). Methodologically, it's a qualitative research, through a bibliographic review.
\end{abstract}

Keywords: John Rawls, Principles of justice, Equal liberties, Democratic equality, Difference principle.

\section{INTRODUÇÃO}

Na contemporaneidade, a filosofia moral e política tem se ocupado da elaboração de diferentes concepções de justiça, questão das mais importantes na busca pela efetiva realização da justiça social. John Rawls $^{3}$ foi o precursor desses estudos no século XX, sendo o

\footnotetext{
${ }^{1}$ Mestranda do Programa de Pós-Graduação em Direito da Universidade Federal de Pelotas - UFPel. E-mail: julianalsegat@gmail.com.

${ }_{2}^{2}$ Professor Adjunto de Direito da Universidade Federal de Pelotas - UFPel. Doutor em Educação pela Universidade Federal de Santa Maria - UFSM. E-mail: valmorscottjr@ gmail.com

3 John Rawls (1921-2002) foi um filósofo político americano dentro da tradição liberal. Lecionou na Universidade de Harvard por mais de trinta anos (WENAR, 2017).
} 
responsável por reavivar esse interesse filosófico no tema (SEN, 2011), principalmente após a publicação, em 1971, da obra Uma teoria da justiça.

A importância de Rawls e das ideias trazidas em Uma teoria da justiça reverberam até os dias de hoje. Foi a partir de seus ensinamentos que uma série de filósofos resgatou o interesse em pensar sobre justiça social, e pensá-la não somente em termos de atos pessoais ou de leis, mas também em termos de sociedade.

Por meio de sua Teoria, Rawls tentou desenvolver uma concepção liberal e igualitária de justiça social, para uma sociedade democrática (CONSANI, 2016). Ainda que a teoria rawlsiana tenha ensejado a formulação de respostas e críticas, estudá-la a partir de sua obra inicial é, aqui, entendido como essencial para a compreensão das ideias e possibilidades de justiça na atualidade. Neste sentido, justifica-se o presente estudo, cujo objetivo consiste em apresentar de forma resumida ${ }^{4}$ algumas das principais e mais conhecidas formulações de Rawls na obra citada, como a posição original, o véu da ignorância, a estrutura básica da sociedade e os princípios de justiça a ela aplicáveis. Metodologicamente, trata-se de um estudo de cunho qualitativo, por meio de revisão bibliográfica.

\section{SOBRE A POSIÇÃO ORIGINAL, A ESTRUTURA BÁSICA DA SOCIEDADE E A ESCOLHA DOS PRINCÍPIOS DE JUSTIÇA PARA AS INSTITUIÇÕES}

Rawls (2016) explica que a sua teoria da justiça pode ser dividida em duas partes: a primeira consiste em uma interpretação da situação inicial e uma formulação dos princípios disponíveis para escolha; a segunda reside em um argumento que demonstre quais desses princípios seriam adotados de fato.

O objetivo dessa teoria é refutar o utilitarismo (GARGARELLA, 1999) e fundamentar uma sociedade livre e justa. Para tanto, é necessário saber como distribuir os bens e direitos dentro da sociedade, o que se faz por meio de regras e princípios justos. Mas, como formular essas regras e princípios?

Se perguntarmos aos sujeitos sociais, cada um, provavelmente, se inclinará a favorecer seus próprios interesses. Por exemplo, é provável que se questionássemos uma pessoa rica, ela dispensaria educação e saúde públicas, por não serem estas necessidades suas.

\footnotetext{
${ }^{4}$ Ainda que se concorde com Sen (2011, p. 83) quando afirma que todo resumo é basicamente "um ato de barbárie", sobretudo quando se trata de tema tão bem articulado e complexo como o que se pretende enfrentar.
} 
Rawls propõe, por isso, que se faça um acordo hipotético. No entanto, não nos moldes clássicos das teorias contratualistas ${ }^{5}$, pois mesmo que se chegasse a um consenso, este refletiria "o maior poder de barganha de alguns sobre os dos demais" (SANDEL, 2015, p. 178), e isso não representaria um acordo justo.

Em vez disso, ele propõe uma ficção: a posição originária, onde as pessoas, ao se reunirem para escolherem aqueles princípios, estariam cobertas por um véu de ignorância, sem saber temporariamente a que categoria pertencem na sociedade, quem realmente são: qual sua classe, gênero, raça, etnia, religião, seus talentos. Tampouco saberiam suas vantagens e desvantagens dentro da sociedade: se saudáveis ou não, com alto grau de escolaridade ou não, nascidas em uma família estruturada ou não (SANDEL, 2015). Nessa posição, elas só suporiam que as pessoas em geral têm interesses em bens primários sociais (direitos, liberdades, oportunidades, renda) ${ }^{6}$ e deliberariam sobre os princípios que vão reger a criação e distribuição desses bens. "É assim que Rawls entende um contrato social - um acordo hipotético em uma posição original de equidade" (SANDEL, 2015, p. 178).

Importante observar, no entanto, que Rawls parte do pressuposto de que as partes presentes na posição original são representadas, não em um sentido político, mas sim, como "representantes de uma linhagem contínua de reivindicações", introduzindo já aí a questão da justiça intergeracional $^{7}$ (CONSANI, 2016, p. 80). Além disso, ele pressupõe que essas partes, na posição original, estão diante de certas circunstâncias da justiça: são partes racionais, diante de uma escassez moderada (ou seja, recursos naturais e outros não são abundantes), mutuamente desinteressadas, que consideram restrições formais ao conceito de justo e situadas sob o já citado véu da ignorância (CONSANI, 2016).

Na mesma linha, de acordo com Gargarella (1999),

\footnotetext{
${ }^{5}$ Os mais conhecidos autores contratualistas clássicos são Thomas Hobbes (O Leviatã, 1675), John, Locke (Segundo tratado sobre o governo civil, 1682) e Jean-Jacques Rousseau (O Contrato Social, 1762).

${ }^{6}$ Conforme ensina Sen (2011, p. 90), "A análise de Rawls da equidade na distribuição dos recursos invoca um índice do que ele chama de 'bens primários', que são meios gerais úteis para alcançar uma variedade de fins (quaisquer recursos que sejam em geral úteis para as pessoas obterem o que desejam, por mais variados que esses desejos possam ser). Rawls considera que os bens primários incluem coisas como 'direitos, liberdades e oportunidades, renda e riqueza, e as bases sociais da autoestima'. Observem que as liberdades ingressam aqui novamente, dessa vez apenas como um recurso que complementa outros recursos, como a renda e a riqueza." Vale referir que, para Rawls (2016), as liberdades e oportunidades são definidas pelas normas das instituições; a distribuição de renda e riqueza são regidas por elas. Ademais, Rawls (2016) esclarece que outros bens primários, como saúde, vigor, inteligência, imaginação, são bens naturais, e não sociais, de modo que, ainda que sofram a influência da estrutura básica da sociedade não são por ela controlados.

${ }^{7}$ Rawls sustenta, na seção 44, que a sociedade presente deve fazer uma poupança (que pode consistir em investimentos, prédios, educação, etc.) para contribuir com as gerações futuras, partindo do pressuposto de que também usufruiu de algo deixado pela geração anterior (RAWLS, 2016).
} 
los principios resultantes del contrato rawlsiano vienen a aplicarse a sociedades bien ordenadas, en donde reinan las circunstancias de justicia. Una sociedad bien ordenada es aquella que está orientada a promover el bien de sus miembros. [...] en la que no existe ni una extrema escasez ni una abundancia de bienes; en donde las personas son más o menos iguales entre sí (en cuanto a sus capacidades físicas y mentales) y, también, vulnerables frente a las agresiones de los demás [...]. (GARGARELLA, 1999, p. 35).

A ficção da posição original é, portanto, utilizada por Rawls como uma ferramenta para definir os princípios de justiça em uma sociedade ideal (HANSHAW, 2018). Nessa posição seria possível escolher princípios imparciais - porque descolados dos interesses pessoais de cada um, já que se está sob o véu da ignorância - e justos para reger a estrutura básica da sociedade.

Relevante notar que esses princípios "no se orientan a resolver casos particulares, problemas cotidianos de justicia. Los principios defendidos por Rawls aparecen, más bien, como criterios destinados a aplicarse en relación con la 'estructura básica de la sociedade"” (GARGARELLA, 1999, p. 35).

Observa-se, nessa afirmação a presença de uma das inovações trazidas por Rawls para a teoria política: a concepção de Justiça para além das ações individuais e das leis, apresentando-a como uma virtude das sociedades e de sistemas econômicos (SANCHEZ, 2016).

De fato, Rawls defende que, nessa situação inicial de igualdade, seriam escolhidos dois princípios de justiça social, cujo objeto primeiro seria a estrutura básica da sociedade, "a organização das principais instituições sociais em um esquema único de cooperação" (RAWLS, 2016, p. 65).

Conforme ensina Wenar (2017), a justiça como equidade de Rawls busca descrever um arranjo justo para as principais instituições políticas e sociais de uma sociedade liberal, como, por exemplo, a Constituição, o sistema de leis, a economia, a família, etc. São essas as instituições responsáveis por distribuir os principais benefícios e fardos da vida social: direitos e deveres, quem terá reconhecimento, quem receberá quais direitos básicos, quem terá oportunidades em quais tipos de emprego, qual será a distribuição de renda e riqueza, e assim por diante (WENAR, 2017). É por isso que são elas os objetos dos princípios de justiça.

Nessa linha, tais princípios devem, em suma, i) estabelecer e reger direitos e deveres dentro dessas instituições (que compõem a estrutura básica da sociedade); e, ii) definir a 
distribuição apropriada dos benefícios e encargos da vida social, regulando a distribuição das vantagens sociais e econômicas (RAWLS, 2016).

Ainda, de acordo com Álvaro de Vitta na apresentação da edição brasileira de Uma teoria da justiça,

os arranjos institucionais básicos da sociedade devem oferecer o suporte necessário - no que se refere a direitos, liberdades, oportunidades e recursos sociais escassos - para que cada um seja capaz de fazer algo de valioso de sua própria vida segundo suas próprias luzes e viver de acordo com suas próprias convicções morais. (RAWLS, 2016, p. XXI)

Isso porque, esclarece Vitta, para Rawls, sob o pluralismo moral contemporâneo, um Estado justo

não pode impor uma visão única do bem, da excelência humana ou daquilo que tem um valor moral supremo. A tolerância com relação aos fins últimos é uma condição para o respeito mútuo entre cidadãos que divergem em sua concepções [...] Se discordamos sobre como devemos viver, podemos [...] nos colocar de acordo sobre termos equitativos de cooperação social que permita a cada um [...] viver de acordo com suas próprias convicções sobre o que confere valor moral à vida humana. (RAWLS, 2016, p. XX).

Tanto o é que Consani (2016, p. 78) destaca que a teoria da justiça como equidade rawlsiana traz um liberalismo marcado "não pela negação da intervenção do Estado na economia, como nas teorias do laissez-faire, mas pela defesa da prioridade do justo sobre o bem."

E quais seriam, afinal, esses princípios? Em Uma teoria da justiça, Rawls desenvolve seu raciocínio de forma complexa e fragmentada, até chegar a uma formulação definitiva dos princípios e dos motivos pelos quais seriam escolhidos. Para entendê-lo, vale mencionar desde logo suas duas principais ideias orientadoras.

Wenar (2017) explica que, para Rawls, a cooperação social é necessária para que os cidadãos possam levar uma vida decente. Ela é, portanto, pressuposto para a justiça conforme por ele formulada. No entanto, os cidadãos não são indiferentes a como os benefícios e encargos da cooperação serão divididos entre eles. Atentos a isso, os princípios de justiça elaborados por Rawls articulam as ideias liberais centrais de que a cooperação deve ser justa para todos os cidadãos considerados livres e iguais. Interessante pontuar, aqui, que, para ele, em uma "sociedade bem-ordenada, que é regulada de forma eficaz por uma concepção compartilhada de justiça, também há um entendimento público sobre o que é justo e injusto" 
(RAWLS, 2016, p. 67-68). De acordo com Wenar (2017), a interpretação que Rawls dá a esses conceitos pode ser vista como uma combinação de uma tese negativa e de uma positiva.

A tese negativa reside na ideia de que os cidadãos não merecem nascer numa família rica ou pobre, nascer naturalmente mais ou menos dotados que os outros, nascer mulher ou homem, nascer como membro de uma determinada raça, grupo e assim por diante. Essas seriam características moralmente arbitrárias, razão por que os cidadãos não teriam direito a mais benefícios da cooperação social apenas por terem nascido com tais atributos. Por exemplo, o fato de um cidadão ter nascido rico, branco e homem não fornece, por si, razão para esse cidadão ser favorecido pelas instituições sociais (WENAR, 2017).

Esta tese negativa, entretanto, não diz como os bens sociais devem ser distribuídos. A tese distributiva positiva de Rawls é a da reciprocidade baseada na igualdade. Todos os bens sociais devem ser distribuídos igualmente, a menos que uma distribuição desigual seja vantajosa para todos. A ideia norteadora é a de que, uma vez que os cidadãos são fundamentalmente iguais, o raciocínio a respeito da justiça deve partir da suposição de que os bens produzidos cooperativamente devem ser igualmente divididos. A justiça, então, exige que quaisquer desigualdades beneficiem todos os cidadãos e, particularmente, devem beneficiar aqueles que têm menos. A igualdade, portanto, define a linha de base. A partir daí, qualquer desigualdade deve melhorar a situação de todos e, especialmente, a dos mais desfavorecidos (WENAR, 2017). As ideias ligadas às arbitrariedades morais e aos requisitos de igualdade e vantagem recíproca são, assim, marcas e fundamentos da teoria da justiça em análise.

Assentadas essas premissas, Rawls defende que, na posição original, os dois princípios escolhidos seriam um sistema de liberdades iguais para todos - em última análise, direitos civis e políticos - e um sistema em que as desigualdades econômicas e sociais são permitidas se respeitarem o princípio da diferença e a igualdade equitativa de oportunidades (de ocupar cargos públicos, de responsabilidade, de autoridade).

Cada um desses princípios se aplicaria a uma parte da estrutura básica da sociedade. O primeiro se aplicaria "aos aspectos do sistema social que definem e garantem as iguais liberdades fundamentais" e o segundo "aos aspectos que especificam e estabelecem as desigualdades sociais e econômicas" (RAWLS, 2016, p. 74).

Na seção 11 de Uma teoria da justiça, o autor formula de forma provisória esses dois princípios de justiça. Segundo Rawls defende, na posição original, os indivíduos escolheriam 
os dois princípios de justiça, segundo a seguinte formulação: "Primeiro: cada pessoa deve ter um direito igual ao sistema mais extenso de iguais liberdades fundamentais que seja compatível com um sistema similar de liberdades para as outras pessoas" (RAWLS, 2016, p. 73).

Ou seja, liberdades individuais/fundamentais iguais, que não são absolutas na medida em que podem se chocar com a liberdade dos outros, ocasiões em que poderão ser limitadas ou comprometidas (RAWLS, 2016).

Segundo: as desigualdades sociais e econômicas devem estar dispostas de tal modo que tanto (a) se possa razoavelmente esperar que se estabeleçam em benefício de todos como (b) estejam vinculadas a cargos e posições acessíveis a todos. (RAWLS, 2016, p. 73).

Em outra palavras, a distribuição de renda e riqueza não precisa ser igual, desde que isso seja vantajoso para todos - mais adiante ele aprimora essa ideia -; e a estruturação de organizações que fazem uso de diferenças de autoridade e responsabilidade devem ter seus cargos acessíveis para todos (RAWLS, 2016).

O primeiro princípio ${ }^{8}$ (liberdades iguais) é prioritário sobre o segundo, havendo, assim, uma "ordem serial" entre ambos (CONSANI, 2016, p. 82). Desse modo, a violação a iguais liberdades não pode ser justificada ou compensada por maiores vantagens econômicas e/ou sociais (RAWLS, 2016). Nesse sentido, o segundo princípio deve ser compatível com as liberdades fundamentais e com a igualdade de oportunidades.

Embora ele estabeleça a prioridade da liberdade, indica um rol daquelas que considera mais importantes:

a liberdade política (o direito ao voto e a exercer cargos públicos) e a liberdade de expressão e reunião, a liberdade de consciência e de pensamento; a liberdade individual, que compreende a proteção contra a opressão psicológica, a agressão e a mutilação (a integridade da pessoa); o direito à propriedade pessoal e a proteção contra a prisão e detenção arbitrárias, segundo o conceito de Estado de Direito. (RAWLS, 2016, p. 74).

A partir disso, Rawls constrói uma concepção provisória e mais geral de justiça, segundo a qual "Todos os valores sociais devem ser distribuídos de forma igual, a não ser que uma distribuição desigual de um ou de todos os valores seja vantajosa para todos" (2016, p.

\footnotetext{
${ }^{8}$ Em O liberalismo político (originalmente lançado em 1993), Rawls aprimora a ideia sobre o primeiro princípio, referindo que este poderia ser precedido "de um princípio lexicamente anterior, que prescreva a satisfação das necessidades básicas dos cidadãos, ao menos à medida que a satisfação dessas necessidades básicas seja necessária para que os cidadãos entendam e tenham condições de exercer de forma fecunda esses direitos e liberdades" (RAWLS, 1993, p. 49-50).
} 
75). Ou seja, a injustiça seria equivalente a desigualdades que não sejam vantajosas para todos (RAWLS, 2016).

$\mathrm{O}$ autor salienta que esses princípios se destinam a regular arranjos institucionais básicos, aplicando-se às instituições. Isso significa dizer que os direitos e liberdades fundamentais a que se referem esses princípios são definidos pelas normas públicas da estrutura básica (aquelas que definem quais serão os direitos e liberdades, deveres, etc.). Assim, é possível inferir que esses princípios se aplicariam prioritariamente ao estágio legislativo (RAWLS, 2016), à fase de produção legislativa, que seria por eles guiada.

Imaginar a distribuição dos bens primários sociais em uma situação hipotética inicial permite que se tenha um ponto de referência para avaliar melhorias. Se nessa situação inicial, distribuídos os bens primários, as desigualdades de riqueza e diferenças de autoridade deixassem todos em melhor situação, então essas desigualdades seriam justas (em acordo com a concepção geral) (RAWLS, 2016).

Voltando aos dois princípios, o primeiro deles (liberdade igual) só requer que as leis definidoras de liberdades fundamentais se apliquem a todos e que "permitam a mais abrangente liberdade compatível com uma liberdade semelhante para todos" (RAWLS, 2016, p. 77). O único motivo para restringir liberdades é que, se isso não fosse feito, umas interfeririam nas outras.

No que diz respeito ao segundo princípio, Rawls destaca que, por se aplicar a formas institucionais, refere-se "às expectativas dos indivíduos representativos" (RAWLS, 2016, p. 78), e não de indivíduos nomeados, individualizados.

Para entender essa colocação, antes de continuar com a análise dos princípios, mostra-se pertinente abordar o que o autor chama, na seção 16 de sua obra, de "posições sociais relevantes" (RAWLS, 2016, p. 113).

Segundo ele, "ao aplicarmos os dois princípios da justiça à estrutura básica, colocamo-nos na posição de certos indivíduos representativos e examinamos como o sistema lhes parece" (RAWLS, 2016, p. 114). Porém, nem todas as posições sociais serão relevantes para esses fins. As posições sociais relevantes são os "pontos de partida generalizados e agregados de uma forma apropriada" para fins de decisão quanto à divisão dos benefícios da cooperação social (RAWLS, 2016, p. 114). É a partir da visão delas que é possível ter um ponto de vista mais amplo. A teoria rawlsiana sustenta que cada pessoa ocupa duas posições 
relevantes: a de cidadão igual e a definida pelo seu lugar na distribuição de renda e riqueza (RAWLS, 2016).

Na posição de cidadão igual, o indivíduo representativo tem um ponto de vista mais geral. A partir dela é possível avaliar a estrutura básica, arbitrar exigências das liberdades, analisar questões de política social e interesses comuns, que beneficiam a todos de forma semelhante, como, por exemplo, questões de saúde, seguridade e segurança (RAWLS, 2016).

Na posição definida pelo lugar do sujeito na distribuição de renda e riqueza estão os indivíduos representativos daqueles que têm expectativas diferentes em relação aos bens primários atribuídos desigualmente. Eles são, então, classificados pelos níveis de renda e riqueza. É a partir disso que Rawls (2016) tenta definir quem são os menos favorecidos, o fazendo segundo cada um de três tipos de contingências por ele apontadas (considerando-se que todos estejam num âmbito de normalidade, com capacidade física e psicológica): i) $1^{\mathrm{a}}$ contingência: pessoas com origem familiar/classe mais desfavorecidas; ii) $2^{\mathrm{a}}$ contingência: pessoas cujos talentos não permitem se dar tão bem; e, iii) $3^{\text {a }}$ contingência: pessoas cuja sorte no decorrer da vida revela-se menos feliz.

Em suma, "a justiça como equidade analisa o sistema social partindo" dessas duas posições: de cidadania igual e dos diversos níveis de renda e riqueza (RAWLS, 2016, p. 118). Rawls ressalta, contudo, que às vezes será preciso levar em conta outras posições, como quando houver direitos básicos desiguais fundamentados, o que ocorre no caso, por exemplo, de características naturais fixas (raça, sexo, cultura).

O alerta, é o de que "É essencial que julgamentos feitos a partir da perspectiva das posições relevantes prevaleçam" sobre julgamentos particulares (RAWLS, 2016, p. 118). E o argumento para tanto é o de que nem todos se beneficiam sempre com o que os dois princípios exigem se pensarmos em nós mesmos a partir das nossas situações particulares.

Tais posições especificam, pois, um ponto de vista geral a partir do qual se devem aplicar os dois princípios de justiça à estrutura básica (RAWLS, 2016). Diante disto,

Ao escolhermos os supostos pontos de partida, obedecemos à ideia de mitigar as consequências do acaso natural e das circunstâncias sociais. Ninguém deve beneficiar-se dessas contingências, a não ser que redundem no bem-estar dos outros. (RAWLS, 2016, p. 119).

Superada tal questão e retomando a abordagem sobre os princípios de justiça formulados em Uma teoria da Justiça, o segundo princípio exige que "todos se beneficiem das desigualdades permissíveis na estrutura básica" (RAWLS, 2016, p. 78). Ou seja, deve ser 
razoável que, dentro dessa estrutura, cada indivíduo representativo prefira suas perspectivas com a desigualdade a suas perspectivas sem ela (RAWLS, 2016).

Aqui, as diferenças na distribuição de renda ou em posições de autoridade/responsabilidade não podem ser justificadas com base no argumento de que desvantagens dos que se encontram em uma posição são contrabalançadas com vantagens maiores de outros. Existem várias maneiras de proporcionar vantagens a todos quando uma situação inicial de igualdade - a posição original - é tida como ponto de referência (RAWLS, 2016).

Mas, como escolher dentre essas possibilidades? Rawls entende que para fazer tal escolha é preciso especificar os princípios (RAWLS, 2016). É nesse ponto (seção 12) que o autor passa a esmiuçar o segundo princípio. Segundo Rawls, há quatro interpretações possíveis para ele em razão das expressões "benefícios de todos" e "acessíveis a todos"9. $\mathrm{O}$ autor elabora uma tabela com as combinações possíveis a partir das duas partes do segundo princípio, a fim de apontar as possibilidades que daí advêm (RAWLS, 2016, p. 79). Adaptamos essa tabela a fim de possibilitar uma melhor compreensão, conforme segue:

$\begin{array}{ll} & \begin{array}{l}\text { Interpretações para "benefício } \\ \text { de todos" }\end{array} \\ \begin{array}{l}\text { Interpretações para "acessíveis } \\ \text { a todos" }\end{array} & \begin{array}{l}\text { Princípio da eficiência } \\ \text { Igualdade na forma de }\end{array} \\ \begin{array}{l}\text { carreiras acessíveis aos } \\ \text { talentos }\end{array} & \begin{array}{l}\text { natural: sistema de liberdade } \\ \text { mercado, com liberdade igual e } \\ \text { igualdade apenas formal. Não } \\ \text { há um esforço social para } \\ \text { assegurar igualdade de } \\ \text { fato/material. Estado não } \\ \text { intervém para ajustar } \\ \text { contingências sociais. }\end{array} \\ & \end{array}$

Igualdade na forma de (3) Igualdade liberal: sistema oportunidades equitativas

liberal com base na meritocracia - estado ajusta contingências sociais, mas ainda há desigualdades provenientes de talentos e aptidões naturais, cujo mérito não pode ser assumido pelo
Interpretações para "benefício de todos"

Princípio da diferença

(1) Aristocracia natural

(4) Igualdade democrática: combina igualdade equitativa de oportunidade com o princípio da diferença; leva em conta que além de contingências sociais, também interferem na situação de cada indivíduo a loteria natural, é

\footnotetext{
${ }^{9}$ Interessante notar que Rawls supõe que o primeiro princípio (liberdade igual) tem sempre o mesmo sentido.

${ }^{10}$ Princípio segundo o qual, em apertada síntese, uma configuração é eficiente sempre que é impossível modificá-la para melhorar a situação de um sem piorar a de outro.
} 
indivíduo.

dizer, as aptidões e talentos com que cada ser nasceu - algo cujo mérito não é nosso.

Tabela 1: As quatro possibilidades de interpretação do segundo princípio de justiça. Adaptada de RAWLS, 2016, p. 79.

Sandel (2015) nos traz exemplos que permitem a inteligibilidade sobre os significados possíveis para o segundo princípio ao trazer a discussão sobre a arbitrariedade moral. A depender da combinação, teremos níveis diferentes de conivência/aderência com as arbitrariedades morais e seremos levados a diferentes teorias de justiça.

A primeira seria o sistema de aristocracia feudal ou sistema de castas (1), considerando-os injustos "porque distribuem renda, riqueza, oportunidade e poder de acordo com o nascimento" (SANDEL, 2015, p. 190). A injustiça reside no fato de as perspectivas de vida do indivíduo dependerem desse fato arbitrário - o nascimento em uma ou outra posição social. Fazendo a analogia com uma corrida, nesse sistema alguns corredores sequer poderiam participar da competição.

A segunda seriam as sociedades de mercado (2) (correspondente à teoria libertária de justiça ou, para Rawls, à liberdade natural). Nelas, os indivíduos "têm garantidas as mesmas liberdades básicas, enquanto a distribuição de renda e riqueza é determinada pelo livre mercado" (SANDEL, 2015, .p. 191). Há, portanto, igualdade formal; porém, o Estado não se preocupa em concretizar essa igualdade e em reparar desigualdades de oportunidades. Adotando aquela analogia, aqui todos poderiam participar da corrida e competir, mas uns sairiam na frente de outros. Ou seja, as oportunidades não são iguais. E isso faz deste um sistema injusto, pois há permissão no sentido de que a divisão dos bens sociais seja influenciada por fatores moralmente arbitrários, como a posição de nascimento em uma família mais ou menos abastada.

A terceira é a concepção meritocrática (3), que propõe remediar as diferenças sociais e econômicas ao oferecer oportunidades iguais de educação para todos. Há, aqui, uma reparação de contingências sociais. O objetivo é o de que pessoas nascidas em famílias mais pobres possam competir em situação de igualdade com aqueles que têm origem econômica ou social privilegiada. Nesse sistema, instituem-se programas assistenciais, compensatórios, educacionais e treinamento profissional. Por esta concepção, a distribuição de renda e riqueza resultante do livre mercado só é justa "se todos tiverem as mesmas oportunidades para 
desenvolver suas aptidões" (SANDEL, 2015, p. 192). Pensando em uma corrida, aqui todos poderiam participar partindo da mesma linha de largada.

Contudo, ainda que Rawls concorde que o sistema meritocrático corrija algumas vantagens moralmente arbitrárias (como o nascimento em família abastada), isso não é suficiente para ser considerado justo (SANDEL, 2015). Utilizando o exemplo da corrida, Sandel (2015) argumenta que, mesmo assim, sabemos quem serão os vencedores: os corredores mais velozes. E isso, no entender de Rawls, decorre apenas em parte do mérito do indivíduo. Há uma parcela que se relaciona com contingências do ponto de vista moral, tanto quanto nascer em uma família rica (SANDEL, 2015). Para a teoria rawlsiana,

ainda que funcione à perfeição na eliminação da influência das contingências sociais, ainda assim permite que a distribuição da riqueza e da renda seja determinada pela distribuição natural de aptidões e talentos. [...] as parcelas distributivas são decididas pelo resultado da loteria natural; e esse resultado é arbitrário do ponto de vista moral. (RAWLS, 2016, 89).

A partir do esboço das interpretações indicadas pelos sistemas (1), (2) e (3), Rawls refere que para a elaboração da justiça como equidade é preciso decidir qual é a interpretação preferível. E, nesse ponto, antecipa que a preferível é a igualdade democrática (4) (sobre a qual se tratará a seguir), porque o que ele busca é uma interpretação que trate a todos como pessoas morais "e que não meça a parcela de cada pessoa nos benefícios e encargos da cooperação social segundo sua sorte social ou loteria natural de aptidões e talentos" (RAWLS, 2016, p. 90).

Com essas considerações, o autor passa a se debruçar sobre o sistema de igualdade democrática e o princípio da diferença (seção 13). Como visto na Tabela 1, a igualdade democrática combina o postulado da igualdade equitativa de oportunidades com o princípio da diferença.

O princípio da diferença (que está contido na primeira parte do segundo princípio de justiça) seleciona uma posição específica a partir da qual as desigualdades econômicas e sociais devem ser julgadas. Assim, presumindo-se uma estrutura básica das instituições que atenda à liberdade igual e à igualdade equitativa de oportunidades, as expectativas mais elevadas dos que estão em melhor situação somente serão justas se fizerem parte de um esquema que eleve as expectativas dos membros mais desfavorecidos. Esta é uma concepção igualitária no sentido de que, se não houver uma distribuição que melhore a situação de ambas as partes, deve-se preferir a distribuição igualitária para todos (RAWLS, 2016). 
Rawls (2016) defende que o princípio da diferença é compatível com o princípio da eficiência: quando ele se satisfaz totalmente, é impossível melhorar a situação de qualquer indivíduo representativo sem piorar a de outro. Essa compatibilidade só existe, no entanto, se o esquema for totalmente justo (aí também será totalmente eficiente). Quando não for assim, a justiça terá prioridade sobre a eficiência, o que pode requerer mudanças não eficientes.

De outro lado, o autor aponta que "a ampla difusão dos benefícios" é favorecida quando verificadas duas características nas instituições: i) que sejam estabelecidas para promover certos interesses fundamentais que todos têm em comum; ii) que cargos e posições sejam abertos a todos (RAWLS, 2016). Ainda, há possibilidade de uma ligação em cadeia e entrelaçamento das expectativas: "parece provável que se a autoridade e poderes dos legisladores e juízes, por exemplo, melhoram a situação dos menos favorecidos, melhoram também a dos cidadãos em geral" (RAWLS, 2016, p. 99). Em outras palavras, se melhorar a situação de quem está em posição desfavorável, provavelmente melhorará também a situação dos demais.

Diante destas e outras considerações - cujo espaço não nos permite avançar -, Rawls propõe o enunciado renovado do segundo princípio ${ }^{11}$ (lembrando que aquele $1^{\circ}$ enunciado trazido ao início era provisório, prévio à especificação acima exposta):

As desigualdades sociais e econômicas devem estar dispostas de tal modo que tanto (a) propiciem o máximo benefício esperado para os menos favorecidos, como (b) estejam vinculadas a cargos e posições abertos a todos em condições de igualdade equitativa de oportunidades. (RAWLS, 2016, p. 100).

Observe-se, aqui, a substituição da expressão "benefício de todos" (contida na formulação provisória) pelo princípio da diferença (exigindo que as desigualdades sejam dispostas de modo que favoreçam os menos privilegiados).

Conforme destaca Hanshaw (2018), é possível dizer que esse segundo princípio reconhece e aceita que, até a implementação da justiça como equidade, haverão desigualdades econômicas e sociais. Por isso, exige que, até tal implementação, as desigualdades sejam organizadas de modo que sejam consideradas justas.

Especificado o princípio da diferença, Rawls passa a analisar a segunda parte do segundo princípio, o qual exige que as desigualdades estejam vinculadas a cargos e posições

\footnotetext{
${ }^{11}$ Gargarella destaca que o princípio foi assim apresentado por Rawls no seu trabalho original (Uma teoria da justiça), mas atenta que o filósofo "ha ido variando parcialmente la presentación de tales principios" (GARGARELLA, 1999, p. 39).
} 
abertos a todos em condições de igualdade equitativa de oportunidades (seção 14). Hanshaw (2018) destaca que esse princípio nos traz a ideia de que as pessoas similarmente dotadas e motivadas devem ter acesso igual aos cargos e posições, independentemente de serem ricas ou pobres.

Porém, como "se entiende que nadie merece sus mayores talentos o capacidades, el esquema de justicia no se considera satisfecho con una mera igualdad de oportunidades" (GARGARELLA, 1999, p. 39). É sempre necessário que esta esteja acompanhada do princípio da diferença.

Rawls argumenta que "a função do princípio das oportunidades equitativas é garantir que o sistema de cooperação social seja um sistema de justiça procedimental pura ${ }^{12 "}$ (RAWLS, 2016, p. 105). Se esse princípio for satisfeito - explica ele -, seria possível deixar a justiça distributiva por sua própria conta.

No ponto, vale reiterar que a distribuição dos itens produzidos pela sociedade é feita de acordo com o sistema público de normas. Este define o quê, quanto e por quais meios produzir. Além disso, esse sistema define as exigências (expectativas) legítimas ${ }^{13}$ que, quando cumpridas, produzem a distribuição resultante. Assim, na justiça procedimental pura, "a precisão da distribuição se fundamenta na justiça do sistema de cooperação do qual provém e no atendimento às reivindicações dos indivíduos nela engajados" (RAWLS, 2016, p. 106).

Ainda, é importante salientar que a concepção dos dois princípios de justiça não interpreta o problema principal da justiça distributiva como um problema da justiça alocativa. Nesta, o conjunto alocado não é produção dos indivíduos com os quais serão divididos os bens, esses indivíduos não estão envolvidos em relações de cooperação e, já que não há exigências prévias, a distribuição se dá de acordo com desejos e necessidades, o que leva ao utilitarismo (RAWLS, 2016) que o autor busca combater.

\footnotetext{
${ }^{12}$ Rawls diz que se verifica a justiça procedimental pura quando "existe um procedimento correto ou justo que leva a um resultado também correto ou justo, [...] contanto que tenha sido aplicado o procedimento" (RAWLS, 2016, p. 104). O exemplo é o jogo de apostas. Se estabelecemos uma aposta de livre e espontânea vontade, sem trapaças, a distribuição dos valores da aposta ao ganhador é justa, ou ao menos não será injusta. O autor aponta que para que haja a aplicação da justiça procedimental pura às parcelas distributivas é necessário estabelecer e administrar de maneira imparcial um sistema justo de instituições. É preciso que a estrutura básica seja justa, ou seja, com uma constituição justa e com a organização justa das instituições sociais e econômicas: estrutura básica justa tem procedimento justo (RAWLS, 2016).

${ }^{13}$ Rawls (2016) propõe definir as expectativas dos cidadãos como um índice de bens primários. Estes seriam a base das expectativas, que são legítimas quando o indivíduo cumpre sua parte quanto ao que se exige para o recebimento desses bens.
} 


\section{A TENDÊNCIA IGUALITÁRIA DOS PRINCÍPIOS DE JUSTIÇA}

Vimos até aqui como seria feita, na teoria rawlsiana, a escolha dos princípios necessários para reger uma sociedade justa e quais seriam os princípios escolhidos em uma situação inicial de igualdade. Vimos, também, ainda que de forma sintetizada, qual a lógica que guia a elaboração desses princípios. A partir dessas informações é possível avançar a fim de demonstrar que os princípios analisados efetivamente expressam uma concepção igualitária de justiça. Rawls aborda essa questão na seção 17 de Uma teoria da justiça.

Inicialmente, o autor esclarece que o princípio da diferença não é o mesmo que o princípio da reparação. Segundo este, as desigualdades imerecidas (contingências sociais e loteria natural, por exemplo) exigem reparação, o que se faria dando mais atenção aos menos favorecidos no que diz com condições sociais e dotes naturais (RAWLS, 2016),. O princípio da diferença não é o da reparação porque ele não exige que a sociedade tente contrabalançar as deficiências dos indivíduos como se se esperasse que todos competissem em igualdade de condições na mesma corrida.

Sandel (2015) aclara essas afirmações por meio de um exemplo. Durante a especificação do segundo princípio, vimos que havia quatro interpretações possíveis que conduziam a diferentes teorias de justiça. Para entendê-las, utilizamos o exemplo da competição em uma corrida, chegando à conclusão de que, ainda que todos os participantes saiam do mesmo ponto de partida, saberemos de antemão que os vencedores serão os mais velozes. O princípio da reparação, isoladamente, se preocuparia apenas em compensar isso, colocando os mais lentos para largarem antes ou pedaços de chumbo nos tênis dos mais rápidos. Outro exemplo é dado por Rawls (2016): pelo princípio da reparação, talvez fossem despendidos mais recursos com a educação dos menos inteligentes, e não dos mais inteligentes, pelo menos durante os primeiros anos da escola.

Não é isso que busca o princípio da diferença. Este objetiva corrigir a distribuição desigual de aptidões e talentos naturais não por meio de limitações aos mais talentosos, mas sim incentivando-os a produzir e entendendo que os ganhos vindos a partir disso, por não serem mérito apenas da pessoa afortunada na loteria natural, devem beneficiar a todos da sociedade, em especial os menos privilegiados (SANDEL, 2015).

Sob essa ótica, em verdade, o princípio da diferença realiza em parte os objetivos do princípio da reparação. Ele 
transforma os objetivos da estrutura básica de modo que o sistema total de instituições deixe de salientar a eficiência social e os valores tecnocráticos. O princípio da diferença representa, com efeito, um acordo no sentido de se considerar a distribuição dos talentos naturais em certos aspectos como um bem comum, e no sentido de compartilhar os benefícios econômicos e sociais maiores propiciados pelas complementaridades dessa distribuição. (RAWLS, 2016, p. 121).

O princípio da diferença sustenta que os que foram favorecidos pela natureza, quem quer que sejam, só podem se beneficiar de sua boa sorte quando isso melhorar a situação dos desafortunados. Ninguém merece sua capacidade natural ou seu ponto de partida na sociedade. Por isso, os mais favorecidos devem se beneficiar de sua boa sorte não apenas por serem mais talentosos, mas sim "para cobrir os custos de educação e treinamento dos menos favorecidos" e para que usem seus talentos de modo a beneficiá-los/ajudá-los (RAWLS, 2016, p. 121).

O autor salienta que o intuito não é ignorar ou eliminar essas diferenças, mas sim organizar a estrutura básica de modo que elas atuem em prol de todos, especialmente dos menos afortunados. Ou seja, "de modo que ninguém ganhe ou perca devido ao seu lugar arbitrário na distribuição dos dotes naturais ou de sua posição inicial na sociedade sem dar ou receber benefícios compensatórios em troca" (RAWLS, 2016, p. 122). Entende-se que esse pensamento poderia servir a justificar, por exemplo, ações afirmativas e programas de transferência condicionada como o Bolsa-Família.

Em trecho que Sandel destaca como "emocionante" (2015, p. 204), Rawls defende seu entendimento e refuta uma posição conformista quanto a uma suposta inerente deficiência das instituições que acarretaria em inevitável injustiça:

Podemos rejeitar o argumento de que a organização das instituições é sempre deficiente, porque a distribuição dos talentos naturais e as contingências das circunstâncias sociais são injustas, e essa injustiça deve, inevitavelmente, transportar-se às instituições humanas. De tempos em tempos essa ponderação é apresentada como desculpa para ignorar a injustiça, como se recusar-se a aquiescer à injustiça fosse o mesmo que a incapacidade de aceitar a morte. A distribuição natural não é justa nem injusta; nem é injusto que se nasça com determinada posição social. Isso são meros fatos naturais. Justo ou injusto é o modo como as instituições lidam com esses fatos. (RAWLS, 2016, p. 122).

Por isso a proposta de que, na justiça como equidade, os indivíduos concordem em só se beneficiarem das contingências da natureza e das contingências sociais quando isso gerar um benefício comum (RAWLS, 2016). 
Outro ponto do princípio da diferença em prol da concepção igualitária é que ele traz benefícios mútuos, embora, à primeira vista, possa parecer enviesado em favor dos menos favorecidos. Todos se beneficiam desse esquema, pois o bem-estar de cada um depende da cooperação social, e só se pode esperar que as pessoas cooperem voluntariamente se as condições do esquema forem razoáveis para todos (RWALS, 2106). Rawls (2016) lembra que em um sistema de cooperação justo, com uma estrutura de normas públicas e de expectativas geradas por essa estrutura, aqueles que fizeram o que o sistema promete que recompensará têm o direito a terem suas expectativas satisfeitas.

E é nesse sentido que os mais afortunados têm direito a sua melhor situação. Em suma, "têm direito a tudo o que possam obter em conformidade com as normas de um sistema equitativo de cooperação" (RAWLS, 2016, p. 124). O que os indivíduos mais favorecidos social ou naturalmente não têm é o direito a um esquema de cooperação que autorize a obtenção de benefícios ainda maiores sem a correspondente contribuição para vantagens dos outros. Isso porque, repita-se, não se merece o lugar inicial na sociedade e a distribuição de aptidões inatas, assim como é problemático saber até que ponto "merecemos o caráter superior que nos possibilita fazer o esforço de cultivar nossas capacidades" (RAWLS, 2016, p. 124), pois isso depende de contingências familiares e sociais (como, por exemplo, o quanto os pais incentivaram um filho, desde a primeira infância, a desenvolver suas habilidades).

Outro mérito do princípio da diferença é dar uma interpretação ao princípio da fraternidade, em particular no tocante à ideia de não ter/querer vantagens maiores a menos que isso favoreça quem está em pior situação (RAWLS, 2016). Note-se que o filósofo faz tal apontamento não só como uma questão de regra, mas de senso de justiça dos cidadãos.

Tais considerações permitem a Rawls vincular os ideais de liberdade, igualdade e fraternidade com os dois princípios de justiça por ele propostos. A liberdade corresponderia ao primeiro princípio, a igualdade à ideia de igualdade contida no primeiro princípio (liberdade igual) e de igualdade equitativa de oportunidades; e a fraternidade ao princípio da diferença. Este seria a expressão do significado fundamental da fraternidade do ponto de vista da justiça social (RAWLS, 2016).

Por fim, Rawls assegura que, por transformar os objetivos da sociedade em aspectos fundamentais, essa concepção democrática de justiça esboçada a partir dos dois princípios não corre o risco de tornar uma sociedade em meritocrática (RAWLS, 2016) - o que ele sustenta 
ser indesejado porque há, nesse sistema, grande desigualdade social, cultural e de poder, que se concentra nas mãos de poucos, atuando em prol dos interesses destes.

Entende-se que as observações traçadas neste capítulo contemplam os principais elementos que compõem o que Rawls chamou de "esboço da concepção de justiça social expressa pelos dois princípios de justiça para instituições” (RAWLS, 2016, p. 128).

\section{PRINCÍPIOS QUE SE APLICAM A INDIVÍDUOS: PRINCÍPIO DA EQUIDADE E DEVERES NATURAIS}

Até o presente momento, abordaram-se alguns dos principais pontos da teoria rawlsiana na elaboração dos princípios de justiça destinados à estrutura básica da sociedades e suas instituições. Para Rawls (2016), no entanto, uma concepção completa de justiça exige que se pactue, na posição original, princípios da estrutura básica da sociedade, princípios para indivíduos, princípios dos direitos das nações (comportamento dos estados), bem como normas de prioridade para solucionar conflitos principiológicos, nesta ordem.

Sobre os princípios aplicáveis aos indivíduos, o filósofo explica que se dividem em exigências e permissões, conferindo ênfase às exigências. Estas abarcam obrigações, consubstanciadas pelo princípio da equidade, e deveres naturais positivos e negativos.

O princípio da equidade serve para interpretar todas as exigências que são obrigações, e não deveres naturais. Tal princípio afirma que "a pessoa deve fazer sua parte, conforme definido pelas normas da instituição", quando estão presentes duas condições: i) "que a instituição seja justa" (atenda aos 2 princípios de justiça); e, ii) "que a pessoa tenha, de livre e espontânea vontade, aceitado os benefícios desse arranjo ou tirado proveito das oportunidades" que ele oferece para promover seus interesses (RAWLS, 2016, p. 134). A ideia é a seguinte: pessoas que participam da cooperação mutuamente vantajosa restringem suas liberdades para produzir vantagens para todos. Consectário lógico, não devemos lucrar com os esforços dos outros sem termos contribuídos com a nossa quota justa. (RAWLS, 2016).

Esse princípio tem, portanto, duas partes: i) instituições ou práticas justas; ii) atos voluntários exigidos (que podem ser manifestados por compromisso expresso/tácito ou aceitação de benefícios). A primeira formula condições para que a segunda gere obrigações estas são definidas por uma instituição e são devidas por determinados indivíduos (ocupantes 
de cargos públicos e, por exemplo, "aqueles que, estando em melhor situação, promoveram seus objetivos dentro do sistema") (RAWLS, 2016, p. 139-140).

No tocante aos deveres naturais, Rawls arrola alguns exemplos, como o dever de ajuda mútua, de ajudar ao próximo sem se colocar em risco excessivo (dever positivo), de não prejudicar ou agredir o próximo (dever negativo), de não provocar sofrimento desnecessário (negativo), dever de justiça (RAWLS, 2016). Entre as suas características, estão o fato de se aplicarem independentemente de ato voluntário, de não terem ligação obrigatória com instituições, de seu teor não ser definido por normas dessas organizações, prescindirem de compromisso, vigorarem para todas as pessoas morais (racionais) e não serem devidos apenas a certos indivíduos, mas sim a todos (RAWLS, 2016).

Sobre o dever de justiça, importa notar que traduz uma exigência de apoio e obediência às instituições justas assim como a promoção de arranjos justos ainda não instituídos. Rawls (2016) afirma que se a estrutura básica é justa, todos têm o dever natural de fazer a sua parte, sendo este o mais fundamental, por vincular cidadãos em geral e não requerer atos voluntários. Além das exigências, há permissões, dentre as quais se destacam as supererrogatórias (como atos de bondade, misericórdia, heroísmo, autosacrifício).

\section{CONSIDERAÇÕES FINAIS}

No presente artigo procurou-se apresentar, ainda que de forma incipiente, os principais pensamentos de Rawls, articulados na obra Uma teoria da justiça, para a formulação dos princípios que ele entende que seriam escolhidos para reger a estrutura básica da sociedade em uma situação inicial de igualdade.

Neste livro, Rawls se propôs a oferecer uma alternativa ao utilitarismo, apresentando uma configuração de sociedade democrática na qual os cidadãos, em um posição inicial igualitária, sem saberem suas origens e características, e, portanto, seus interesses individuais, escolheriam a liberdade e a igualdade democrática para regerem suas instituições. Sua ideia de justiça como equidade, de admissão das desigualdades tão somente se estas beneficiarem a todos, e, em especial, os menos favorecidos, é um resgate do princípio da fraternidade e uma olhar humanizado para um contexto liberal. Seus pensamentos descortinaram a possibilidade de imaginar uma sociedade de indivíduos livres, porém, não individualistas; uma sociedade 
em que os sentimentos de comunidade e de cooperação atuem de forma a viabilizar que todos tenham a oportunidade de alcançarem suas próprias concepções de bem.

Muitas foram as críticas que se apresentaram desde o lançamento de sua obra, tanto por autores de tradição liberal, como por autores de outras vertentes políticas e econômicas . Apesar disso, a concepção rawlsiana de justiça, em especial os princípios analisados, são de suma importância para a construção de um pensamento e de normas que objetivem uma sociedade justa, democrática, que tenha como pressuposto a igualdade entre os indivíduos.

As abstrações e ficções utilizadas pelo filósofo, embora não isentas de críticas, servem, sem dúvida, para um exercício teórico sobre como uma sociedade poderia alcançar a justiça social conciliando ideais de liberdade e igualdade, e quais seriam as circunstâncias ideais para que isso fosse viabilizado. Esse exercício, que para alguns pode ser considerado utópico, é um passo em direção à constatação de situações desiguais e à criação de ferramentas justas para sua correção.

Ainda que a teoria não forneça todas as respostas ${ }^{14}$, é notória sua relevância, não só pela solidez com que se apresenta, mas também pelo estímulo aos filósofos morais e políticos contemporâneos no sentido de desenvolverem suas próprias concepções de justiça e aprimorarem as ideias lançadas por Rawls - além de estimulá-lo a, ele próprio, aprimorar sua tese em obras posteriores, como O liberalismo político (1993), O direito dos povos (1999) e Justiça como equidade (2001).

Os princípios desenvolvidos por Rawls inauguraram um novo olhar sobre as possibilidades de justiça social, no qual "implícita a ideia de uma visão de igualdade poderosa e até mesmo inspiradora" (SANDEL, 2015, p. 194). Pensar sobre justiça e em como concretizá-la perpassa, portanto, a reflexão sobre os seus ensinamentos.

\section{REFERÊNCIAS BIBLIOGRÁFICAS}

CONSANI, Cristiane Foroni. Justiça como equidade ou justiça focada em realizações? As concepções de justiça de John Rawls e Amartya Sen. Saberes: Revista interdisciplinar de Filosofia e Educação, Natal/RN, v.1, n. 13, 31 mar. 2016, p. 76-96. Disponível em: https://periodicos.ufrn.br/saberes/article/view/8404. Acesso em: 03 mai. 2019.

GARGARELLA, Roberto. Las teorías de la justicia después de Rawls. Barcelona: Paidós Estado y Sociedad, 1999.

\footnotetext{
${ }^{14}$ Rawls sequer tinha essa pretensão, o que se verifica inclusive pelo uso do artigo "uma" em vez de "a" ao intitular sua teoria (CONSANI, 2016).
} 
HANSHAW, Hannah. Rawls and Feminism. CLA Journal, n. 6, 2018, p. 182-195.

Disponível em: https://uca.edu/liberalarts/files/2018/09/Rawls-and-Feminism.pdf. Acesso em: 02 ago. 2019.

RAWLS, John. Uma teoria da justiça. 4. ed. rev. Trad. de Jussara Simões; revisão técnica e da tradução Álvaro de Vita. São Paulo: Martins Fontes, 2016.

O liberalismo político. 1. ed. São Paulo: Ática, 1993.

SANCHEZ, Beatriz Rodrigues. Críticas feministas à teoria da justiça rawlsiana: contendas entre posições liberais e não-liberais. Trabalho preparado para apresentação no VI Seminário Discente da Pós-Graduação em Ciência Política da USP, de 2 a 6 de maio de 2016.

Disponível em: file:///C:/Users/jsegat/Downloads/1602-2084-1-PB\%20(1).pdf. Acesso em: 03 ago. 2019.

SANDEL, Michael J. Justiça: o que é fazer a coisa certa. 19. ed. Rio de Janeiro: Civilização Brasileira, 2015.

SEN, Amartya. A ideia de justiça. Trad. de Denise Bottmann e Ricardo Doninelli Mendes. São Paulo: Companhia das Letras, 2011.

WENAR, Leif. John Rawls. The Stanford Encyclopedia of Philosophy (Spring 2017

Edition), Edward N. Zalta (ed.). Disponível em:

https://plato.stanford.edu/archives/spr2017/entries/rawls/. Acesso em 04 mai. 2019. 